DeAr Sir,

\section{FEIGNED BEREAVEMENT}

The authors of the paper 'Feigned bereavement: twelve cases' (Journal, July 1978, 133, 15-19) made two opening points: that most of these cases were variants of the Münchausen syndrome and that feigned bereavement was more common than realized.

The Münchausen syndrome and abnormal illness behaviour describe patterns of behaviour which can form part of a range of psychiatric disorders. The information supplied about the twelve cases of feigned bereavement suggests that the same applies to this syndrome. The presence of depression in all but one case, as the authors point out, suggests a closer affinity to depressive disorders than to the Münchausen syndrome.

These observations have important management implications. Once staff anger at discovering the patient's 'deception' is dealt with, the basic underlying psychiatric disorder requires more specific diagnosis and treatment.

The frequency of feigned bereavement may be underestimated. Not all such cases may reach the hospital, as suggested by the character Charlie Citrine in Saul Bellow's novel, Humboldt's Gift. Following the loss of most of his money, the final blow comes when his mistress, Renata, marries his rival for her attentions. He plunges into a deep depression and masquerades with her illegitimate son as a widower in a Madrid pension. He gets a false passport for the boy by telling the U.S. consul that his wife recently died of leukaemia and a pickpocket has stolen his wallet. At the pension he tells the landlady that his wife was killed by a truck as she stepped off the curb in Barcelona, her chest crushed, her lungs punctured, her face destroyed. He rages and yet yearns. His grief and loss are real, although the drama and ever-changing details of his feigned bereavement resemble the cases of Snowden and his colleagues. Their paper brings systematic description into an area of anecdotes, allowing for the testing of more consistent management approaches.

New York University Medical Center,

John Mann

School of Medicine,

550 First Avenue,

New York, N.Y. 10016

DeAr Sir,

Following the report of twelve cases of feigned bereavement (Journal, July 1978, 133, 15-19) we would like to comment on two men referred to a general hospital psychiatric unit, both after self- poisoning following the alleged loss of a female partner.

The first was a truculent man of 34 who claimed to be a teacher with a first-class history degree. The only son of a 'small Northern town prostitute', he had risen by his own efforts, but twelve months previously he had witnessed the death of his wife and son at the hands of a hit-and-run motorist. Since then he had drifted about, hopeless and bereft.

The second patient was 25 , posing convincingly as a solicitor. He told an elaborate tale about his rise from humble origins to a first-class law degree. However, three months before he had lost his fiancée in a car accident in which he was the driver, and since then had been unable to work, had hallucinations of her presence and was weighed down with guilt.

The patients showed many additional similarities in their presentation. For example, both overdosed at the local bus station, neither gave us any means of checking his story, and both used professional books or documents to appear more convincing.

Their course in hospital was identical. Initially they evoked much sympathy and anxiety about their welfare. Later, when confronted, they attempted to maintain their position by subtle shifts in their story, and it eventually emerged that neither of them was bereaved nor a member of any profession, but further information was impossible to obtain. When their request for in-patient treatment was refused they became abusive and discharged themselves and were lost to follow-up.

The diagnosis of the Münchausen syndrome with a psychiatric presentation fits these patients well. This diagnosis has also been previously reported in a patient who presented as depressed subsequent to an alleged incident in Vietnam, where he had gone on the 'rampage' with a gun in a dissociated state. It seems that Münchausen patients characteristically prefer a spectacular and tragic role, and syndromes such as bereavement by sudden death and 'combat dissociative reaction' provide suitable vehicles for deception.

Bames Unit Psychiatric Consultation Service,

Lee Holland

Radcliffe Infirmary,

Oxford

\section{Reference}

Gelenberg, A. J. (1977) Münchausen's syndrome with a psychiatric presentation. Diseases of the Nervous System, May, 38, 378-80.

[This correspondence is now closed.-Editor] 